\title{
Drug-induced changes in dentate nuclei of cerebellum
}

Sir,

We read with great interest the article titled "Sequential MR imaging (with diffusion-weighted imaging) changes in metronidazole-induced encephalopathy" by Singh et al. in the April-June 2017 issue of the Indian Journal of Radiology and Imaging. ${ }^{[1]}$ The article is highly informative and describes signal changes in splenium and dentate nuclei following metronidazole ingestion. In this article, we describe a few drugs that cause similar signal changes in the cerebellar dentate nuclei [Table 1]:

Thus, we see that the dentate nuclei can be affected by many drugs with nonspecific magnetic resonance imaging findings. Hence, integration of clinical data is crucial for definitive diagnosis.

Table 1: Drugs that cause signal change in dentate nuclei

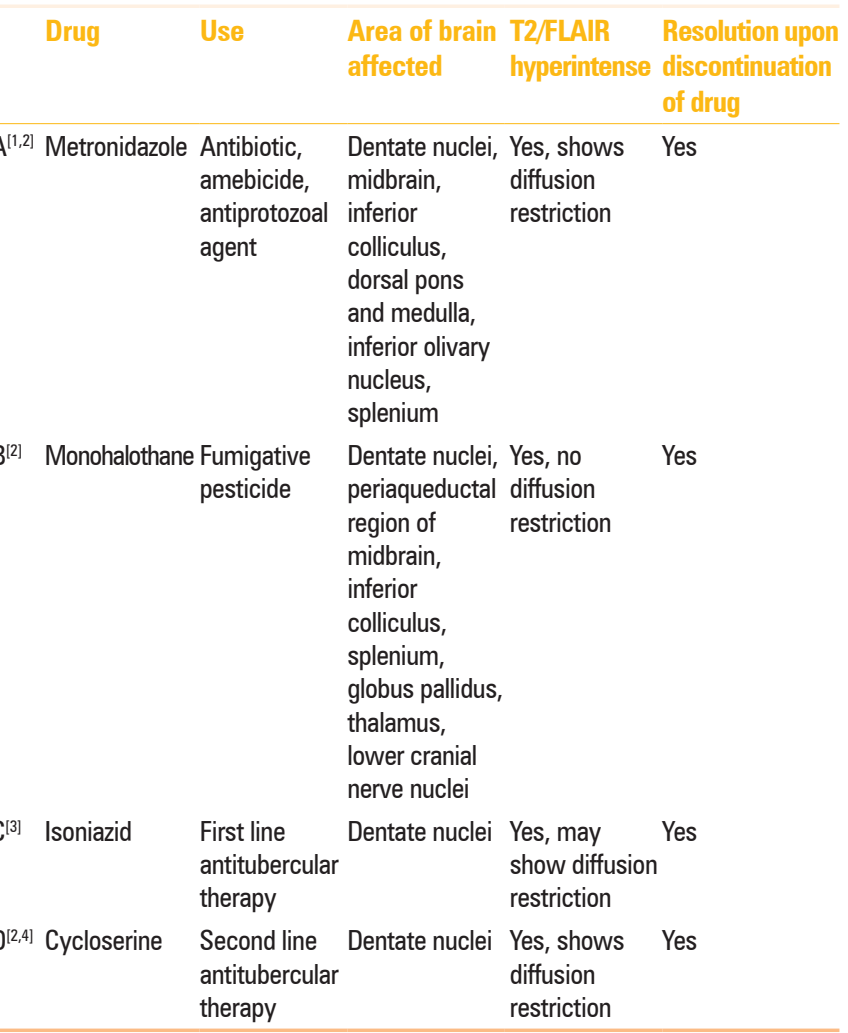

Financial support and sponsorship

Nil.

Conflicts of interest

There are no conflicts of interest.

\section{Yashant Aswani, Nishant Aswani', Rohit Sharma²}

Department of Radiology, $\mathrm{PMCH}$, Udaipur, 'Department of Neurology, GB Pant Hospital, New Delhi, India, ${ }^{2}$ Department of Internal Medicine, Hamad Medical Corporation, Doha, Qatar. E-mail: nishant_udr@yahoo.co.in

\section{References}

1. Singh R, Kaur R, Pokhariyal P, Aggarwal R. Sequential MR imaging (with diffusion-weighted imaging) changes in metronidazole-induced encephalopathy. Indian J Radiol Imaging 2017;27:129-32.

2. Khadilkar S, Jaggi S, Patel B, Yadav R, Hanagandi P, Faria do Amaral LL. A practical approach to diseases affecting dentate nuclei. Clin Radiol 2016;71:107-19.

3. Peter P, John M. Isoniazid-induced cerebellitis: A disguised presentation. Singapore Med J 2014;55:e17-9.

4. Kim S, Kang M, Cho JH, Choi S. Reversible magnetic resonance imaging findings in cycloserine-induced encephalopathy: A case report. Neurol Asia 2014;19:417-9.

This is an open access journal, and articles are distributed under the terms of the Creative Commons Attribution-NonCommercial-ShareAlike 4.0 License, which allows others to remix, tweak, and build upon the work non-commercially, as long as appropriate credit is given and the new creations are licensed under the identical terms.

\begin{tabular}{|l|l|}
\hline \multicolumn{2}{|c|}{ Access this article online } \\
\hline Quick Response Code: & \\
\hline & Website: \\
\hline & www.jri.org \\
\cline { 2 - 3 } & \\
\hline
\end{tabular}

Cite this article as: Aswani $\mathrm{Y}$, Aswani $\mathrm{N}$, Sharma R. Drug-induced changes in dentate nuclei of cerebellum. Indian J Radiol Imaging 2018;28:480.

๑ 2018 Indian Journal of Radiology and Imaging | Published by Wolters Kluwer - Medknow 